\title{
Musculoskeletal Tuberculosis in Dermatomyositis: Association or Coincidence?
}

\author{
Andressa Silva Abreu, Geórgea Hermogenes Fernandes, Eduardo Ferreira Borba, \\ Lissiane Karine Noronha Guedes, Jéssica Fernandes Ramos, Samuel Katsuyuki Shinjo
}

Division of Rheumatology and Infectious Disease Department, Hospital das Clínicas da Faculdade de Medicina da Universidade de São Paulo, São Paulo, Brazil.

Email: samuel.shinjo@gmail.com

Received November $20^{\text {th }}, 2013$; revised December $20^{\text {th }}, 2013$; accepted December $28^{\text {th }}, 2013$

Copyright (C) 2014 Andressa Silva Abreu et al. This is an open access article distributed under the Creative Commons Attribution License, which permits unrestricted use, distribution, and reproduction in any medium, provided the original work is properly cited. In accordance of the Creative Commons Attribution License all Copyrights (c) 2014 are reserved for SCIRP and the owner of the intellectual property Andressa Silva Abreu et al. All Copyright @ 2014 are guarded by law and by SCIRP as a guardian.

\section{ABSTRACT}

Dermatomyositis is a rare idiopathic inflammatory myopathy characterized by proximal muscle weakness associated with typical skin abnormalities and compatible electromyographic finds. Tuberculosis could determine several clinical manifestations but the classic one is the lung presentation. Among the extra pulmonary manifestations of tuberculosis, the musculoskeletal form is rare and it is usually a direct extension of the bone involvement nearby. In the present study, the authors described two dermatomyositis patients and musculoskeletal tuberculosis. In both cases, there was presence of bilateral tenosynovitis, which is considered atypical for further infectious.

\section{KEYWORDS}

Dermatomyositis; Tenosynovitis; Tuberculosis

\section{Introduction}

Dermatomyositis is a rare idiopathic systemic inflammatory myopathy characterized by progressive muscle weakness of proximal limbs associated with skin abnormalities such as heliotrope and Gottron's papules [1,2].

Opportunistic infections occur in $6.3 \%$ to $21.3 \%$ of dermatomyositis/polymyositis patients [3-7]. This high prevalence in part is due to the chronic use of corticosteroids and/or immunosuppressives to control the disease.

Tuberculosis is one of these opportunistic infections, but there are few studies reporting this mycobacteriosis in dermatomyositis/polymyositis [8-16]. In fact, tuberculosis has a broad spectrum of clinical manifestations [17], including a rare musculoskeletal type that corresponds to less than $5 \%$ of all types of tuberculosis $[17,18]$.

Concerning to this musculoskeletal tuberculosis form, skeletal or arthritis tuberculosis is more frequent whereas muscle and/or tendon tuberculosis is rare, accounting for $1 \%$ of cases of such tuberculosis cases [18-20]. In this study, we report two dermatomyositis patients with mus- culoskeletal tuberculosis (tenosynovitis) due to its rarity and scarcity of coexistence.

\section{Case Reports}

\subsection{Patient 1}

A black female patient, 59-year-old, with definite dermatomyositis diagnosis [1,2] performed in 2006. At the time, she presented the typical rash (heliotrope and Gottron's papules), and proximal muscle weakness of the four members for three months, increase of muscle enzymes [creatine kinase 18,000 IU/L (reference value: 24-173 IU/L), aldolase 20.6 IU/L (reference value 1.0 to $7.5 \mathrm{IU} / \mathrm{L})$ ], proximal myopathy of the members in electromyography and no evidence of neuropathy, muscle biopsy consistent with inflammatory myopathy. In 2011, after three relapses, the disease was considered under clinical and laboratorial control. At this time, she was taking azathioprine $3 \mathrm{mg} / \mathrm{kg} / \mathrm{day}$, methotrexate $25 \mathrm{mg} /$ week and prednisone $12.5 \mathrm{mg} / \mathrm{day}$, when she developed 
progressive swelling and pain in hands and wrists (Figure 1(A)) for two months, with no other symptoms. Laboratory tests showed C-reactive protein $3.1 \mathrm{mg} / \mathrm{L}$, erythrocyte sedimentation rate $5 \mathrm{~mm} / 1 \mathrm{st}$ hour, leukocytosis up to 9070 cells $/ \mathrm{mm}^{3}$. Hands ultrasonography showed flexor tendons tenosynovitis, involving the carpus and the forearms, fluid collection in the left forearm and subcutaneous edema positive doppler. Punctured collection showed positive polymerase chain reaction test for Mycobacterium tuberculosis DNA (polymerase chain reaction Mtb), while the detection of other infectious agents was negative. Pulmonary computer tomography scan showed no evidence of tuberculosis. Started treatment with rifampicin $450 \mathrm{mg} /$ day, isoniazid $225 \mathrm{mg} /$ day, pyrazinamide $1200 \mathrm{mg} /$ day, ethambutol $825 \mathrm{mg} /$ day as recommended by national health authorities [21] and the patient evolved with significant improvement in the first month of treatment (Figure 1(B)).

\subsection{Patient 2}

A white male patient, 52-year-old, with a definite diagnosis of dermatomyositis [1,2] in 2004. At that time, he had the typical rash (heliotrope and Gottron's papules), and proximal muscle weakness of the four members for three months, an increase of muscle enzymes (creatine kinase $4200 \mathrm{IU} / \mathrm{L}$, aldolase $28.5 \mathrm{IU} / \mathrm{L}$ ), proximal myopathy of the members in electromyography, muscle biopsy consistent with inflammatory myopathy. Throughout the follow-up period, there were two recurrences of the disease despite therapy with prednisone, azathioprine and methotrexate. Six months ago, the disease was under control using methotrexate $25 \mathrm{mg} /$ week, cyclosporine 2 $\mathrm{mg} / \mathrm{kg} /$ day and prednisone $5 \mathrm{mg} /$ day, when he presented pain and swelling in hands and forearms. Laboratory tests showed C-reactive protein $29.8 \mathrm{mg} / \mathrm{L}$, erythrocyte sedimentation rate $16 \mathrm{~mm} / 1 \mathrm{st}$ hour, leukocytosis up to 9140 cells $/ \mathrm{mm}^{3}$. Hands ultrasonography showed flexor tendons tenosynovitis, involving the carpus and the forearms, edema of the subcutaneous tissue positive doppler (Figures 2(A) and (B)). Bilateral tendon synovectomy performed with cultures and tuberculosis DNA research were negative (identification method by polymerase chain reaction). After two weeks, the patient developed fever, worsening edema in the upper member and the appearance of edema in the right leg, associated with proximal hyperpigmented plaques. Biopsy of skin lesions showed granuloma with central necrosis and at this point polymerase chain reaction Mtb was positive. Chest computed tomography showed nodules on the right lung, with areas of necrosis and liquefaction. Started therapy with rifampicin $600 \mathrm{mg} /$ day, isoniazid $300 \mathrm{mg} /$ day, pyrazinamide $1600 \mathrm{mg} /$ day, ethambutol $1100 \mathrm{mg} /$ day and patient evolved with progressive improvement of the

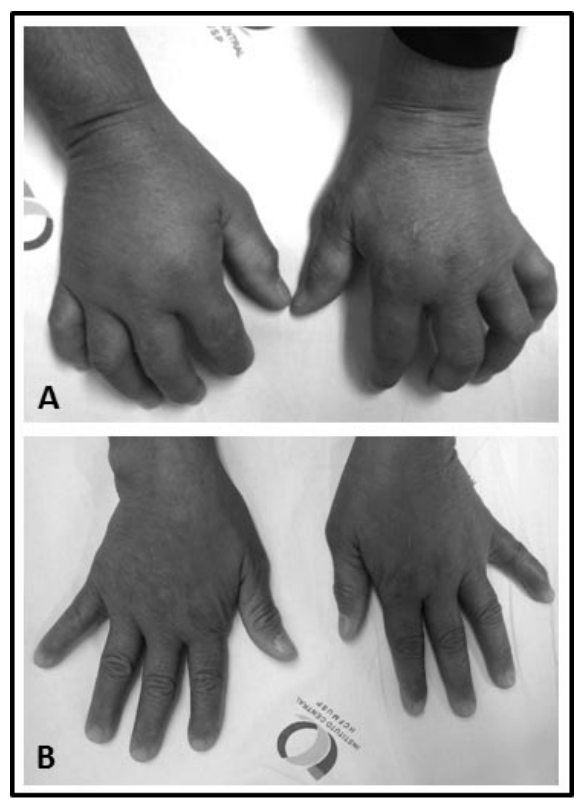

Figure 1. Patient 1: Swelling in hand and wrist as a consequence of tuberculosis. (A) Before and (B) after tuberculosis treatment.

edema of the upper and lower right after two months.

\section{Discussion}

In this study, we present two cases of dermatomyositis patients with musculoskeletal tuberculosis (tenosynovitis). Interestingly, both patients had the remission of their diseases and using two immunosuppressives associated to corticosteroids.

Dermatomyositis/polymyositis patients had $25 \%$ to $37.3 \%$ of several infections, whereas the opportunistic infections occur in $6.3 \%$ to $21.3 \%$ of these cases [3-7]. The presence of esophageal dysmotility (dysphagia) which increases the possibility of aspiration pneumonia, lymphopenia [6], use of immunosuppressive and/or corticosteroids are factors that increase the incidence and frequency of opportunistic infections in dermatomyositis/ polymyositis patients.

Despite the high prevalence of opportunistic infections, few cases of tuberculosis in dermatomyositis/polymyositis were described. In fact, Marie et al. [22] observed nine cases of tuberculosis in a series of 279 patients with dermatomyositis/polymyositis, Chen et al. [7] identified seven cases in 192 dermatomyositis/polymyositis, whereas Airio et al. [11] documented a high prevalence, of 40 cases in 248 patients with dermatomyositis/polymyositis patients. Similarly to these cases [7,11,22], our two patients were using immunosuppressive drugs and glucocosteroids, which may have contributed to the development of tuberculosis.

Tuberculosis could determine several clinical manifestations [17] but the classic one is the lung presentation. 


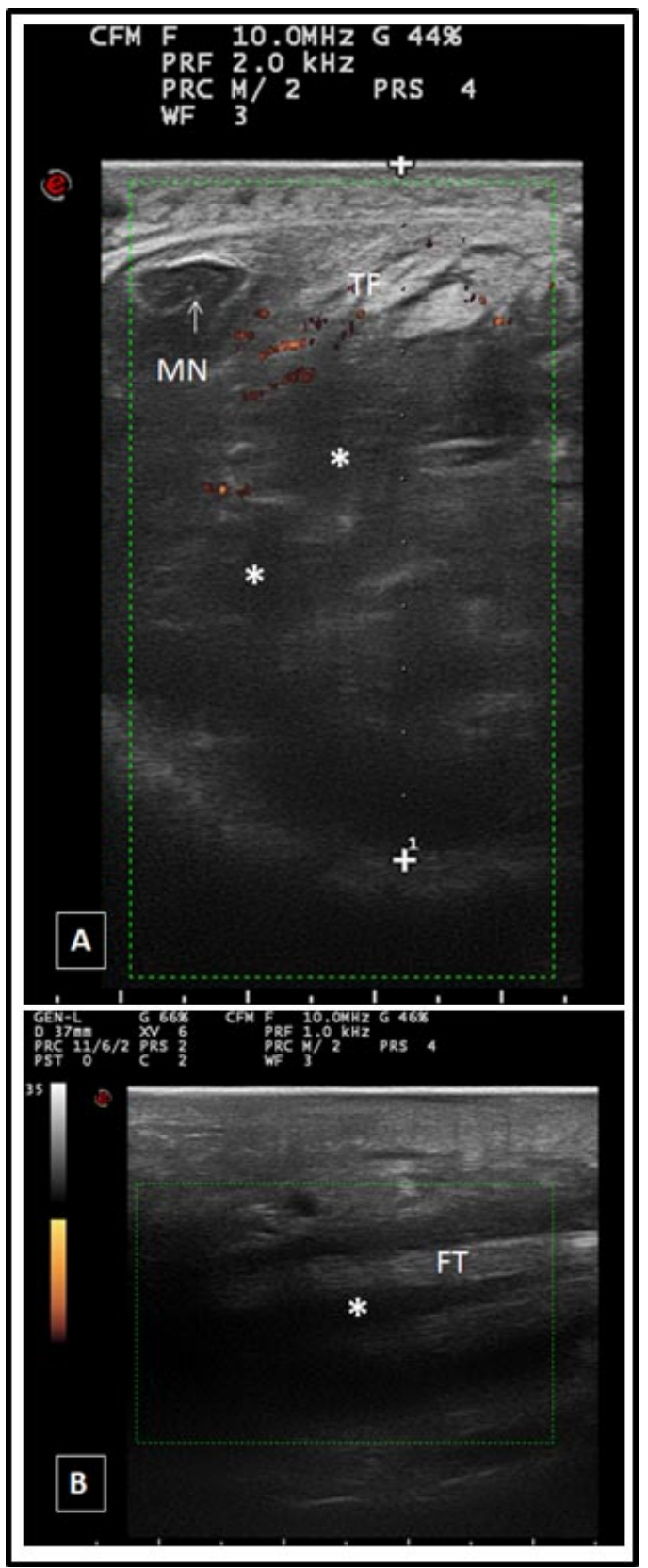

Figure 2. Patient 2: Ultrasound image. High resolution imaging of the left carpal tunnel, showing massive tenosynovitis of the flexor tendons of the fingers, in (A) transverse and (B) longitudinal power doppler positive associated with subcutaneous edema. MN: median nerve, FT: flexor tendons of the fingers; $(*)$ : tenosynovitis.

Among the extra pulmonary manifestations of tuberculosis, the musculoskeletal form is rare and it is usually a direct extension of the bone involvement nearby. Hematogenous dissemination to the muscle is very rare and is usually limited to a tubercular abscess or a set of granulomas [13]. There are few reports of musculoskeletal tuberculosis in dermatomyositis/polymyositis [13-16,20, 21].
The reported cases herein had musculoskeletal tuberculosis affecting tenosynovitis that is rarely described in literature [13-16]. Our patients had flexor tenosynovitis involvement but the muscle involvement and/or tendon corresponded for only $1 \%$ of all cases of musculoskeletal tuberculosis [18-20]. Moreover, in the present study, both patients had atypical infectious manifestations, since affected tenosynovitis bilaterally.

For unknown reasons, the flexors are just more commonly involved than extensors, and the ulnar border is more commonly involved than the radial. Tenosynovitis has a gradual onset and slow progression so the presentation is usually a mild pain swelling and limitation of movement [22].

Because of the atypical presentation, the diagnosis of tenosynovitis tuberculosis is mainly performed by aspiration cytology, biopsy, and imaging with the use of computer tomography, magnetic resonance or ultrasound. In our first case, tuberculosis diagnosis was confirmed by identification of Mycobacterium tuberculosis DNA in forearm subcutaneous collection and, in the second case with the skin biopsy (histopathology and Mycobacterium tuberculosis DNA).

Acid-fast bacilli smear provides rapid results and is widely used, but has low sensitivity. Culture methods for detecting mycobacteria require long incubation times because of slow growth of the organisms, thus the introduction of nucleic acid amplification based tests resulted in improvement for the direct detection of this genus.

Several studies using different targets for amplification in extra pulmonary samples have reported a range of specificity between $77 \%-100 \%[23,24]$. The good sensitivity and specificity of polymerase chain reaction test as well their fast results advocates its use in routine diagnosis of extra pulmonary tuberculosis where the conventional methods are limited. Interestingly, both cases had a significant improvement after tuberculostatic agents.

In summary, although rarely described in the literature, these two cases reinforce the importance of atypical tuberculosis manifestations in dermatomyositis/polymyositis patients with chronic use of immunosuppressives. Early diagnosis and appropriate treatment are indeed the key to a better clinical outcome.

\section{REFERENCES}

[1] A. Bohan and J. B. Peter, "Polymyositis and Dermatomyositis (First of Two Parts)," The New England Journal of Medicine, Vol. 292, No. 7, 1975, pp. 344-347. http://dx.doi.org/10.1056/NEJM197502132920706

[2] A. Bohan and J. B. Peter, "Polymyositis and Dermatomyositis (Second of Two Parts)," The New England Journal of Medicine, Vol. 292, No. 8, 1975, pp. 403-407. http://dx.doi.org/10.1056/NEJM197502202920807 
[3] I. Marie, E. Hachulla, P. Chérin, M. F. Hellot, S. Herson, H. Levesque and P. Y. Hatron, "Opportunistic Infections in Polymyositis and Dermatomyositis," Arthritis and Rheumatism, Vol. 53, No. 2, 2005, pp. 155-165. http://dx.doi.org/10.1002/art.21083

[4] K. P. Ng, F. Ramos, S. M. Sultan and D. A. Isenberg, "Concomitant Diseases in a Cohort of Patients with Idiopathic Myositis during Long-Term Follow-Up,” Clinical of Rheumatology, Vol. 28, No. 8, 2009, pp. 947-953. http://dx.doi.org/10.1007/s10067-009-1181-4

[5] K. Tani, R. Tomioka, K. Sato, C. Furukawa, T. Nakajima, Y. Toyota, T. Shimizu, M. Nakayama, J. Miyata, J. Kishi and S. Sone, "Comparison of Clinical Course of Polymyositis and Dermatomyositis: A Follow-Up Study in Tokushima University Hospital," The Journal of Medical Investigation, Vol. 54, No. 3-4, 2007, pp. 295-302. http://dx.doi.org/10.2152/jmi.54.295

[6] M. Viguier, S. Fouere, P. de la Salmoniere, C. Rabian, C. Lebbe, L. Dubertret, P. Morel and H. Bachelez, "Peripheral Blood Lymphocyte Subset Counts in Patients with Dermatomyositis: Clinical Correlations and Changes Following Therapy,” Medicine (Baltimore), Vol. 82, No. 2, 2003, pp. 82-86. http://dx.doi.org/10.1097/00005792-200303000-00002

[7] I. J. Chen, W. P. Tsai, Y. J. Wu, S. F. Luo, H. H. Ho, L. B. Liou, J. Y. Chen, C. F. Kuo, H. C. Chang, C. H. Yang and K. H. Yu, "Infections in Polymyositis and Dermatomyositis: Analysis of 192 Cases,” Rheumatology (Oxford), Vol. 49, No. 12, 2010, pp. 2429-2437. http://dx.doi.org/10.1093/rheumatology/keq279

[8] C. Mukhopadhyay, A. Garg and A. Ayyagari, "First Documented Cure of a Suggestive Exogenous Reinfection in Polymyositis with Same but Multidrug Resistant $M$. tuberculosis,” BMC Infectious Diseases, Vol. 4, No. 1, 2004, pp. 63-63.

http://dx.doi.org/10.1186/1471-2334-4-63

[9] I. Haq and D. A. Isenberg, "Myositis and Swollen Knees: Disease or Treatment Complication?” Annals of the Rheumatic Diseases, Vol. 61, No. 6, 2002, pp. 544-546. http://dx.doi.org/10.1136/ard.61.6.544

[10] P. Ravn, M. E. Munk, A. B. Andersen, B. Lundgren, L. N. Nielsen, T. Lillebaek, I. J. Soerensen, P. Andersen and K. Weldingh, "Reactivation of Tuberculosis during Immunosuppressive Treatment in a Patient with a Positive Quantiferon-RD1 Test," Scandinavian Journal Infectious Diseases, Vol. 26, No. 6-7, 2004, pp. 499-501. http://dx.doi.org/10.1080/00365540410015222

[11] A. Airio, M. Kauppi, H. Kautiainen, M. Hakala and V. Kinnula, "High Association of Mycobacterial Infections with Polymyositis in a Non-Endemic Country for Tuberculosis," Annals of the Rheumatic Diseases, Vol. 66, No. 10, 2007, pp. 1404-1405. http://dx.doi.org/10.1136/ard.2007.070177

[12] B. Hernandez-Cruz, J. Sifuentes-Osornio, S. Ponce-deLeon Rosales, A. Ponce-de-Leon Garduno and E. DiazJouanen, "Mycobacterium Tuberculosis Infection in Pa- tients with Systemic Rheumatic Diseases: A Case-Series,” Clinical and Experimental Rheumatology, Vol. 17, No. 3, 1999, pp. 289-296.

[13] G. S. Davidson, C. R. Voorneveld and N. Krishnan, “Tuberculous Infection of Skeletal Muscle in a Case of Dermatomyositis," Muscle and Nerve, Vol. 17, No. 7, 1994, pp. 730-732. http://dx.doi.org/10.1002/mus.880170705

[14] K. L. Huang, D. M. Chang and J. J. Lu, "Tuberculosis of Skeletal Muscle in a Case of Polymyositis," Scandinavian Journal of Rheumatology, Vol. 28, No. 6, 1999, pp. 380382. http://dx.doi.org/10.1080/03009749950155391

[15] C. H. Liu, W. C. Liu and L. W. Chen, "Tuberculous Myofasciitis in Dermatomyositis," Clinical of Rheumatology, Vol. 27, Suppl. 1, 2008, pp. S7-S9. http://dx.doi.org/10.1007/s10067-007-0799-3

[16] Y. Yoshida, J. Nakayama, M. Furue and T. Matsuda, "Dermatomyositis with Tuberculous Fasciitis," European Journal of Dermatology, Vol. 14, No. 2, 2004, pp. 123124.

[17] S. K. Sharma and A. Mohan, "Extrapulmonary Tuberculosis,” The Indian Journal of Medical Research, Vol. 120, No. 4, 2004, pp. 316-353.

[18] D. C. Yao and D. J. Sartoris, "Musculoskeletal Tuberculosis," Radiologic Clinics of North American, Vol. 22, No. 4, 1995, pp. 679-689.

[19] G. Garrido, J. Gomez-Reino, P. Fernandez-Dapica, E. Palenque and S. Prieto, "A Review of Peripheral Tuberculous Arthritis," Seminars in Arthritis and Rheumatism, Vol. 18, No. 2, 1988, pp. 142-149. http://dx.doi.org/10.1016/0049-0172(88)90007-8

[20] M. A. Albornoz, M. Mezgarzedeh, C. H. Neumann and A. R. Myers, "Granulomatous Tenosynovitis: A Rare Musculoskeletal Manifestation of Tuberculosis," Clinical of Rheumatology, Vol. 17, No. 2, 1998, pp. 166-169. http://dx.doi.org/10.1007/BF01452268

[21] Portal da Saúde [Homepage on the Internet], Brasília: Ministério da Saúde. Manual de Recomendações para o Controle da Tuberculose no Brasil, 2011.

http://portal.saude.gov.br/portal/arquivos/pdf/manual_de_ recomendacoes_controle_tb_novo.pdf

[22] I. Marie, J. F. Ménard, E. Hachulla, et al., "Infectious Complications in Polymyositis and Dermatomyositis: A Series of 279 Patients," Seminars in Arthritis and Rheumatism, Vol. 41, No. 1, 2001, pp. 48-60. http://dx.doi.org/10.1016/j.semarthrit.2010.08.003

[23] M. M. Al-Qattan, A. Al-Namla, A. Al-Thunayan and M. Al-Omawi, "Tuberculosis of the Hand," The Journal of Hand Surgery, Vol. 36, No. 8, 2011, pp. 1413-1422. http://dx.doi.org/10.1016/j.jhsa.2011.05.036

[24] S. Chakravorty, M. K. Sen and J. S. Tyagi, "Diagnosis of Extra Pulmonary Tuberculosis by Smear, Culture and PCR Using USP Technology," Journal of Clinical Microbiology, Vol. 43, No. 9, pp. 4357-4362. http://dx.doi.org/10.1128/JCM.43.9.4357-4362.2005 